\section{Edited by:}

Shulan Hsieh, National Cheng Kung

University, Taiwan

Reviewed by:

Rolf Verleger, Universität zu Lübeck,

Germany

Motonori Yamaguchi, Edge Hill

University, UK

Yang Seok Cho, Korea University,

South Korea

*Correspondence:

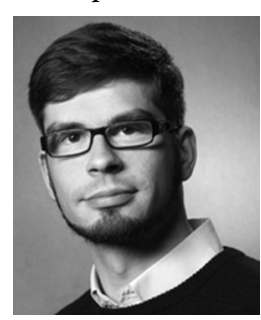

Thomas Dolk investigates mechanisms, modulators, and dysfunctions of executive control in normal and clinical populations on psychological and neural levels of analysis. He studied

Rehabilitation Pedagogics and Sociology at the Martin-Luther-University Halle/Wittenberg. Afterwards, he was funded by a PhD scholarship within the International

Max-Planck-Research-School (IMPRS) at the Max Planck Institute for Human Cognitive and Brain Sciences, Leipzig. He received his $P$ h.D. in psychology from the University of Leipzig in 2013, under the supervision of Wolfgang Prinz and

Roman Liepelt.

dolk@cbs.mpg.de

\title{
The joint Simon effect: a review and theoretical integration
}

\section{Thomas Dolk ${ }^{1,2 *}$, Bernhard Hommel ${ }^{3}$, Lorenza S. Colzato ${ }^{3}$, Simone Schütz-Bosbach ${ }^{4}$, Wolfgang Prinz ${ }^{1}$ and Roman Liepelt ${ }^{5 *}$}

${ }^{1}$ Department of Psychology, Max-Planck-Institute for Human Cognitive and Brain Sciences, Leipzig, Germany

${ }^{2}$ Research Group: Heterogeneity and Inclusion, Faculty of Human Science, University of Potsdam, Potsdam, Germany

${ }^{3}$ Institute for Psychological Research and Leiden Institute for Brain and Cognition, Leiden University, Leiden, Netherlands

${ }^{4}$ Independent Research Group "Body and Self," Max-Planck-Institute for Human Cognitive and Brain Sciences, Leipzig, Germany

${ }^{5}$ Institute for Psychology, University of Muenster, Muenster, Germany

The social or joint Simon effect has been developed to investigate how and to what extent people mentally represent their own and other persons' action/task and how these cognitive representations influence an individual's own behavior when interacting with another person. Here, we provide a review of the available evidence and theoretical frameworks. Based on this review, we suggest a comprehensive theory that integrates aspects of earlier approaches-the Referential Coding Account. This account provides an alternative to the social interpretation of the (joint) go-nogo Simon effect (aka the social Simon effect) and is able to integrate seemingly opposite findings on joint action.

Keywords: joint action, joint Simon effect, social cognition, stimulus-response compatibility, referential coding, review

\section{INTRODUCTION}

Throughout life, people are constantly engaging in social interactions, be it while playing games, dancing, or working toward a common goal together. While doing so, they seem to share an implicit understanding of what joint action means, implies, and requires. The term is typically defined as the ability to coordinate one's own actions with those of others "in space and time to bring about a change in the environment" (Knoblich and Sebanz, 2006; p. 100).

Despite people's intuitive understanding of joint action, its underlying cognitive mechanism(s) are far from being fully understood, however. Scientific research over the last decades improved our understanding of how perception and action are linked (i.e., by sharing common representations; Hommel et al., 2001), how individuals select task-relevant information, predict upcoming actions, and integrate predicted effects of one's own and others' actions (Wilson and Knoblich, 2005). However, this research studied single individuals performing various cognitive and/or behavioral tasks in isolation. Since social beings spend most of their time interacting and communicating with others, a major function of human cognition is likely to facilitate joint action (Frith and Wolpert, 2004; Tomasello et al., 2005; Tomasello, 2009; Hasson et al., 2012). What is unclear, however, is whether processing information about other people and their activities requires special, dedicatedly "social" mechanisms, as some authors have claimed (Sebanz et al., 2006a; Sebanz and Knoblich, 2009), or whether universal informationprocessing mechanisms are sufficient (Hommel et al., 2009; Dolk et al., 2011, 2013a). For instance, while proponents of dedicated social mechanisms tend to take it as self-evident that 
*Correspondence:

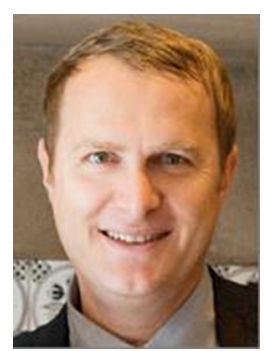

Roman Liepelt studies cognitive psychology and social cognition, with a focus on joint action, action perception and bodily self-perception. In 2006 he received his Ph.D. at the Humboldt

University, Berlin. As a Postdoc he worked at the Max Planck Institute for Human Cognitive and Brain Sciences, Leipzig and as a fellow of the University College London investigating the perception of socially relevant information and action imitation. Since 2010 he is heading a Junior Research Group at the University of Muenster investigating the cognitive and neural processes involved in task sharing with biological and non-biological agents in healthy participants and patients. roman.liepelt@uni-muenster.de synchronizing the behavior of multiple individuals requires the cognitive representation of the others' goals and actions, there are numerous examples of well-synchronized group behavior, such as "schooling" in fish swarms (Shaw, 1978), that are very unlikely to rely on such high level representations. Thus, one of the key questions of today's cognitive science is: how and to what extent do individuals mentally represent their own and others' actions, and how do these representations influence, shape, and constrain an individual's own behavior when interacting with others?

First experimental approaches targeting these issues compared performance on cognitive tasks that were either carried out alone (single setting) or together with another person (joint setting). Quite similar to tennis, say, individuals were thus responsible for the entire performance in the single setting but were taking turns in the joint setting, where they shared labor and responsibility with another person. The most prominent cognitive task that has been tested in single and joint settings is the Simon task (Simon, 1969). Interestingly, performing this Stimulus-Response Compatibility (SRC) task alone (standard Simon task) or when taking turns with another person (joint/social gonogo Simon task) often leads to comparable performance, i.e., a Simon effect (Sebanz et al., 2003), which inspired the idea of human cognition to be mandatorily social (e.g., Tsai and Brass, 2007; Welsh, 2009; Müller et al., 2011a). However, not only has it remained unclear what that actually means but there is also still a considerable lack of understanding of the precise processes governing joint task performance, apart from the fact that more recent findings fail to provide support for a purely social picture of human cognition.

\section{KEY CONCEPT 1 | Stimulus-Response Compatibility (SRC)}

Reflects the amount of compatibility between given stimulus and corresponding response-features. High levels of $\mathrm{SRC}$ are commonly associated with shorter RTs as compared to longer RTs due to low levels of SRC. Beside the Simon effect, the Flanker, the Stroop, and the spatial-numerical association of response codes (SNARC) are classical SRC-paradigms.

In the following, we provide an overview of the basic method and the available findings in the domain of joint action (with a strong focus on the social Simon effect). We will then make an attempt to integrate the available evidence into a comprehensive theory-the Referential Coding Account. As we will point out, this theoretical account provides an alternative to the social interpretation of the (joint) go-nogo Simon effect and explains seemingly contradictory observations from go-nogo Simon task performance.

\section{KEY CONCEPT 2 | Referential Coding}

Is required to discriminate concurrently activated event-representations (e.g., because of endogenous preparation, stimulus-induced activation, and/or cross talk) that refer to conflicting (self- and/or other-generated) action alternatives. Although location is critical in Simon-tasks, other event-features are also likely to enable event discrimination in a given task context.

\section{THE JOINT SIMON PARADIGM}

A tremendous amount of studies provide behavioral as well as neurophysiological evidence for the functional implications of shared representations between action and perception-within and between individuals (e.g., Adolphs, 2003; Wilson and Knoblich, 2005; Amodio and Frith, 2006). For instance, perceiving or imagining another person's actions activates one's own cognitive representations involved in planning and executing similar actions, which has been taken to provide a basic mechanism that enables individuals to identify ongoing actions and to anticipate upcoming action events. However, evidence for the functional equivalence between imagining, perceiving and executing an action (common coding; see Prinz, 1990, 1992, 1997; Hommel et al., 2001, for an extension known as the Theory of Event Coding [TEC]) has been obtained under conditions where participants either passively observed other individuals performing certain actions or where they had to imitate these actions (Brass and Heyes, 2005; Liepelt et al., 2008a, 2010). In contrast, when engaging in joint action, individuals are often required to perform complementary parts of a given task,

\section{KEY CONCEPT 3 | Shared representations}

As cognitive representations are intrinsically individual and private they can only arise and operate in individual minds. Consequentially, shared representations are cognitive representations of two or more individuals that refer to the same reference object/event, thereby being both: private - existing in individual minds - and shared - referring to the same reference. 
i.e., taking turns rather than acting at the same time. How one's own action planning and execution is influenced by the presence of others, their task and their planned and executed actions during social interaction is just beginning to be understood. The most prominent paradigm that has been developed to address this issue is known as the joint Simon paradigm. In this paradigm two participants share a task that in the standard version of the Simon task is performed individually.

\section{THE STANDARD SIMON TASK}

In the standard Simon task, participants are required to carry out spatially defined responses (e.g., left/right key presses) to nonspatial stimulus attributes (e.g., auditory pitch or visual color; Simon, 1969; Simon and Craft, 1970) that randomly appear on the left or right of the participant. For example, participants are instructed to press a right key whenever they perceive a high-pitched tone and a left key in response to a low-pitched tone. Even though stimulus location (left or right) is entirely task-irrelevant, responses are typically faster when they spatially correspond to the stimulus signaling them. That is, spatial Stimulus-Response (S-R) correspondence facilitates task performance, whereas non-corresponding S-R pairs commonly lead to impaired performance-a phenomenon that is known as the Simon effect (SE; Simon, 1990).

The $S E$ has been replicated featuring diverse stimulus displays (e.g., auditory, somatosensory, and visual; see Proctor and Vu, 2006; Hommel, 2011 for reviews) and a variety of S-R arrangements (e.g., horizontal and vertical). Most models explain the SE by assuming that a match between spatial stimulus locations and spatial response locations (or features thereof) facilitates response selection, be it (1) because of a direct association between them (e.g., Kornblum et al., 1990; De Jong et al., 1994) or (2) because the identity of the codes representing these locations (e.g., Hommel, 1993; Hommel et al., 2001), or (3) because attentional shifts appearing in response to the lateralized stimulus presentation prime spatially corresponding action events (e.g., Nicoletti and Umiltà, 1989, 1994). A mismatch between stimulus and response locations in contrast is assumed to create competition between the primed response and the response required by the instruction (dual-route model; Kornblum et al., 1990).

According to this logic, the SE should not be obtained if there is no alternative response (location). Indeed, if the task is turned into a go-nogo task by having participants perform with only one response key, thus eliminating the spatial dimension of the responses (individual or solo go-nogo Simon task), the SE usually disappears (Hommel, 1996). And that makes sense: In the absence of a feature overlap between spatially varying stimuli and responses, S-R relations need no longer to be discriminated and are therefore no longer spatially coded (Liepelt et al., 2011; Hommel, 2013), eliminating the interference caused by competing response tendencies and thus, the $S E$.

\section{THE JOINT SIMON TASK}

Interestingly, however, distributing the complementary go-nogo parts of the standard Simon task across two participants, so that each individual is responsible for operating one of the two buttons in response to their assigned stimulus (i.e., joint/social go-nogo
Simon task), also lead to an SE (Sebanz et al., 2003)—a phenomenon known as the joint Simon Effect (JSE). That is, similar to the standard SE, observed when one participant is responsible for both responses, participants in the joint go-nogo Simon task respond faster if the assigned stimulus spatially corresponded to the actor's response key.

The finding of a JSE has been considered to demonstrate that participants share a complementary, pre-instructed task set and create not only a cognitive representation of their own action but also co-represent (at least) the action of their co-actor (Sebanz et al., 2003). By representing one's own and another person's actions, the spatial dimension of the responses is thought to be represented as well, thereby reintroducing a feature-overlap of spatial S-R dimensions (Sebanz et al., 2003). Like in the standard SE, a match between spatial stimulus locations and spatial response locations facilitates task performance, whereas a mismatch induces response interference (Sebanz et al., 2003; Ferraro et al., 2011). The JSE is thus attributed to action co-representation, which is assumed to be an automatic and dedicated "social" process (Knoblich and Sebanz, 2006; Sebanz et al., 2006a; Sebanz and Knoblich, 2009).

The finding of the JSE and the far-reaching conclusions it has been taken to suggest have ignited further behavioral, neuroscientific, and clinical research investigating the representations underlying the JSE. The following sections will provide a brief overview of these studies.

\section{Behavioral findings}

One of the questions that were tackled by behavioral studies was whether the S-R compatibility effects in the joint action condition depend on the spatial relation between (left and right) stimuli and response keys (response-based compatibility) or on the spatial relation between (left and right) stimuli and responding agents (agent-based compatibility). In contrast to the standard Simon task, in which a single participant is responding with the left and right hand, the joint Simon task requires participants to sit next to each other and to respond with just one hand-usually the right or dominant one. Hence, in the joint Simon task, the spatial origin of the agents' bodies and the spatial origin of the response keys provide two external frames of reference, an agent-based and a response-based frame, respectively. If participants perform the task with uncrossed (right) hands, the two reference frames are fully aligned and therefore confounded. However, when both actors' hands are crossed, with the left sitting person operating the right response key and vice versa, agent-based and response-based coordinates are misaligned and can thus be deconfounded.

Using this rationale, Welsh (2009) found a visual JSE for uncrossed and crossed hand postures irrespective of whether the participants performed the task with the inner (i.e., right hand of the left actor and left hand of the right co-actor) or the outer hands (i.e., left hand of the left actor and right hand of the right co-actor). This result suggests that the JSE is neither dependent on the spatial origin of the responding agents (i.e., external, agent-based coordinates), nor on the anatomical origin of the responding hands (i.e., internal, anatomical coordinates), but rather tied to the spatial location of the response keys (i.e., external, response-based coordinates; Welsh, 2009; but 
see Dolk et al., 2013b; Liepelt et al., 2013, for evidence suggesting some flexibility in coding). Further support highlighting the significance of spatial features in representing alternative action events in joint Simon tasks comes from the so-called transfer-oflearning paradigm, in which participants perform a number of spatially incompatible responses to left and right stimuli before performing the Simon task (i.e., agents on the right respond to stimuli on the left, whereas the agents on the left respond to stimuli on the right; Milanese et al., 2010, 2011; Ferraro et al., 2012). Practicing spatially incompatible responses have been found to reverse the JSE, irrespective of whether co-actors remain the same or change between practice and joint Simon task (Milanese et al., 2011). However, when co-acting individuals changed their seats in between spatially incompatible practice and subsequent joint Simon task, a normal JSE was observed (Milanese et al., 2011; Ferraro et al., 2012), suggesting that participants do not really represent the social identity of co-actor or action but rather the spatial relationship between action alternatives. Since the JSEpolarity flips as a consequence of changing the spatial relations between agents, responses, and stimuli but not when changing the social identity of co-acting agents, one might argue that the underlying cognitive representation is more reliably fed by and thus, more sensitive to its constituting spatial features than to its social features.

Despite the significance of spatial properties, other studies investigated the impact of more conceptual factors. For example, in a study of Tsai et al. (2008), participants thought they were performing a joint Simon task together with an unseen person (biological agent condition) or a computer (non-biological agent condition), while they were actually interacting with a computer program in both conditions. A JSE only occurred in the biological agent condition, indicating that the belief of interacting with an intentional agent can influence the representation of alternative action events (but see Welsh et al., 2007, for evidence against this view). Recently, Sellaro et al. (2013) showed that the belief to interact with an intentional agent alone is not sufficient to induce the JSE, but that this belief has to be attached to a salient spatial event that occurs next to the participant. Interestingly, once such an alternative salient spatial event is established, ongoing sensory feedback is not needed to keep up the cognitive representation thereof and thus for establishing a JSE (Sebanz et al., 2003; Vlainic et al., 2010).

Further studies investigated the influence of interpersonal relationships on the JSE. Human interactions are, by default, perceived to imply positive interdependence, which motivates people to engage in acts of cooperation (Poortvliet and Darnon, 2010). However, there are situations in daily life, such as competitive contexts, where considering other agents too much may be of disadvantage. Results from the JSE indeed seem to support this assumption. While positive mood or a positive relationship with the co-actor elicited a JSE, bad mood (Kuhbandner et al., 2010), intimidating co-actors (Hommel et al., 2009), or actual competition (i.e., instructions to out-perform others; Iani et al., 2011) abolished or drastically decreased the JSE (but see Ruys and Aarts, 2010, for a more complex picture). These findings show that social factors do have some impact on how people represent their own action vis-à-vis those of others. This conclusion is also supported by the observation that the JSE is increased in members of a collectivistic religion (Colzato et al., 2012a) and in individuals that were primed to attend to the social interdependence of their self (Colzato et al., 2012b) or a divergent style of thinking (Colzato et al., 2013).

Another social factor that affects the JSE is the perceived or real similarity between agent and co-agent. For instance, Müller et al. (2011a) observed that the JSE is more pronounced if co-acting with another (videotaped) human than with a (videotaped) Pinocchio, suggesting that the JSE increases with greater similarity between co-actors. Interestingly, however, the decrease of the effect with dissimilar co-actors can be reduced or eliminated by pre-instructing participants to take the perspective of the non-biological co-actor (e.g., Pinocchio; Müller et al., 2011a) or dissimilar human co-actor (e.g., out-group members; Müller et al., 2011b). Similar findings were also observed for human-robot interaction. When two groups of participants were interacting with the same humanoid robot (controlled by a computer program), the mere pre-instruction of interacting with an "intentional" vs. unintentional robot moderated the degree of action-event-representations, leading to a JSE in the intentional but not in the unintentional condition (Stenzel et al., 2012). These findings show that the JSE is sensitive to perceived interpersonal similarity, which can be increased by priming anthropomorphic interpretations (cf., Epley et al., 2007) of actually dissimilar agents.

\section{KEY CONCEPT 4 | Anthropomorphism}

Is the technical term of ascribing human or human-like characteristics, emotion, forms, intentions, motives and many more to animals, events, forces of nature and other things or objects.

\section{Electrophysiological and neuroimaging findings}

Given that the standard Simon effect is commonly assumed to reflect increased response conflict in S-R-incompatible trials (Kornblum et al., 1990), electrophysiological and neuroimaging techniques have been employed to study response-selection processes and response conflict also in joint Simon tasks. Analyses of event-related potentials (ERPs) showed a larger NoGo-P3, a potential that is associated with action control and response inhibition (e.g., Falkenstein et al., 1995; Bokura et al., 2001), for incompatible nogo trials in joint conditions as compared to solo go-nogo or passive co-actor conditions (Sebanz et al., 2006a; Tsai et al., 2006). This finding has been taken to indicate that more inhibitory control was needed on nogo trials in the joint condition, because representations of pre-instructed alternative action events had to be suppressed to fulfill the joint task requirements (Sebanz et al., 2006a; Tsai et al., 2006; Cavallo et al., 2014). Additionally, Tsai et al. (2006) analyzed the Lateralized Readiness Potential (LRP, time-locked to the stimulus onset), an ERP-component assumed to reflect the stimulus-driven preparation of a manual response (i.e., response selection; Coles, 1989). LRPs on compatible nogo trials and incompatible go trials were also significantly larger in the joint as compared to the solo gonogo condition, which was taken to indicate priming effects of cortical responses, corresponding to the co-actor's actions (Tsai et al., 2006). Similar results were obtained when Tsai et al. (2008) 
manipulated the intentionality of the co-actor (see Behavioral Findings).

An fMRI study found stronger activations in medial frontal cortex (MFC) and premotor cortex when participants performed the Simon task together with an active as compared to a passive co-actor, who just rested his/her finger on the alternative response button (Sebanz et al., 2007). This result is in good accordance with other neuroimaging findings highlighting the involvement of MFC, temporoparietal junction (TPJ), superior temporal sulcus (STS), and the temporal poles in social cognition (Adolphs, 2003; Amodio and Frith, 2006; Frith and Frith, 2007). While TPJ, STS, and the temporal poles are typically associated with reasoning about mental states of self and other (e.g., Liepelt et al., 2008b; Spengler et al., 2009; Van Overwalle, 2009), the MFC has been suggested to be involved in monitoring and coding one's own and others' actions (e.g., Frith and Frith, 2007; Radke et al., 2011; Dolk et al., 2012).

\section{Patient studies}

Although the JSE has been shown to be modulated by the perceived intentionality (Tsai and Brass, 2007; Müller et al., 2011a; Stenzel et al., 2012) or perceived agency (Stenzel et al., 2014) of co-acting agents, these findings do not directly indicate an involvement of social reasoning and high-level social cognitive processes. To investigate whether the effect involves, or is related to the attribution of mental states to others (the socalled Theory-of-Mind, ToM; see Premack and Woodruff, 1978), Sebanz et al. (2005b) conducted a study with high-functioning autistic patients. However, although individuals with autism are generally assumed to have deficits in processing social information (Frith, 2001; Frith and Frith, 2010), there was no evidence that autistic individuals performed the joint Simon task any differently than non-autistic controls.

It is important to emphasize that Sebanz et al. (2005b) studied autistic individuals that either passed first or second-order ToMtasks, so that they were able to infer another person's mental state in principle (first order) and to infer one person's beliefs about another person's beliefs (second order; Sebanz et al., 2005b). These abilities are considered to reflect residual social processing capacities (Humphreys and Bedford, 2011) that can potentially account for the observed, basically normal JSE. To test for this possibility, Humphreys and Bedford (2011) compared patients with severe lesions in the frontal lobe with patients having lesions in posterior parietal cortex (PPC) and TPJ. The latter failed both first- and second-order ToM-tasks. Explicitly instructing both patient groups to take the other persons' action into account revealed consistent JSEs in patients with temporoparietal lesions, whereas the JSE decreased over time in patients with frontal lesions. Humphreys and Bedford argued that patients with frontal lesions may have difficulties in preserving sufficient processing resources to maintain the other persons' actions on top of coding one's own action events.

In conclusion, since both lesion groups of Humphreys and Bedford failed in ToM-tasks, the available evidence does not provide clear support for the idea that the JSE relies on a particular social mechanism, interpersonal perception or cognition, or high-level social representation (e.g., mental state attribution).

\section{HOW SOCIAL IS THE JOINT SIMON EFFECT?}

The fact that the presence of another active individual is able to increase response conflict, as evidenced by the emergence of the JSE, indicates that agents must consider this presence in one way or the other. The theoretical challenge is to determine what the critical factor is and how it affects the representation of tasks and actions. Several authors have suggested that the agent may automatically co-represent the co-actors task-share, i.e., the "rule that states the stimulus conditions under which a co-actor should perform a certain action" (Sebanz et al., 2005a; p. 1235). According to this action co-representation account, corepresentation increases the amount of conflict during action selection, which in turn produces the JSE (cf., Sebanz et al., 2003, 2005a, 2006b, 2007; Tsai and Brass, 2007; Vesper et al., 2010; Müller et al., 2011a,b).

Others have argued that the JSE may not reflect the corepresentation of the co-actor's S-R rule but, rather, the corepresentation of the co-actor him/herself (Wenke et al., 2011). This actor co-representation account shifts the focus from the coactors' mere S-R-based activity to their responsibility to act, and it suggests that the action selection conflict does not reflect difficulties with action-event-discrimination (i.e., with respect to which particular action is to be performed) but with self-other discrimination (i.e., with respect to which particular agent is responsible for an action to be performed in a certain moment in time). In other words, the JSE might reflect uncertainty as to whose turn it is to execute the upcoming action (for a similar line of arguments see, the agent identification account; Philipp and Prinz, 2010).

Unfortunately, both of these social approaches fail to explain a number of observations. For one, both would suggest that individual difficulties to represent other people and their actions should reduce or eliminate the JSE, which is inconsistent with the available findings in patients suffering from such difficulties (see Patient Studies). For another, both approaches suggest that the co-actor must actually be an intentional agent or at least be interpreted in anthropomorphic ways. That this is unnecessary was demonstrated by a recent study of Dolk et al. (2011). In several experiments, these authors systematically de-socialized the "joint" Simon task context. First, they showed that a significant "JSE" can be obtained if the actor performs a solo go-nogo Simon task side-by-side a passive observer of the alternative response button that is associated with an attention-attracting event. Next, they demonstrated that the same effect is obtained when the passive observer is absent, suggesting that it was only the attention-attracting event that created the response conflict.

The Dolk et al. (2011) study suggests that neither the integration of another person nor the integration of another person's action into one's own action, task, or body representation is necessary for the JSE to occur. As even non-social events are sufficient to reliably influence an individual's own task performance, it seems to be the presence or expectation of salient events as such that underlies the JSE. Hence, the JSE may be socially induced by the presence of a responding co-actor without necessarily being social in nature. Indeed, Dolk et al. (2013a) observed significant JSEs induced by a Japanese waving cat and a ticking metronome. 
As an alternative to the more "social" accounts, Guagnano et al. (2010) suggested that the co-actor's action may serve no other purpose than providing a spatial reference frame. According to this spatial response coding account, an actor's own action is coded in relation to the other's action-just like in the standard Simon task, where one's own left-hand action provides a spatial reference for the relative coding of one's right-hand action, and vice versa (Hommel, 1996). Based on their results (which showed a JSE with close but not with distant co-actors), Guagnano et al. (2010) further proposed that such a reference frame is effective only if the co-actor is responding in the participant's peripersonal space (i.e., within arm reach), but not if he or she is responding in the participant's extrapersonal space (i.e., outside of reaching distance; but, see Welsh et al., 2013 for a more complex picture). Note that neither the action or actor co-representation account nor the agent identification account can explain this distance effect, which provides some indirect support for the spatial response coding account. Likewise, the spatial response coding account does not require any social attribution processes, so that it can easily deal with the demonstration of reliable JSEs in patient populations in which processes are impaired (see Patient Studies). At the same time, however, the account fails to explain why JSEs should depend on the agent's mood (Kuhbandner et al., 2010), religious attitude (Colzato et al., 2012a), self-construal (Colzato et al., 2012b), style of thinking (Colzato et al., 2013) or on the personal relationship between actor and co-actor (Hommel et al., 2009).

\section{A REFERENTIAL CODING ACCOUNT}

Given the difficulties that social accounts of the JSE have with the effectivity of non-social factors and the opposite problems of the spatial response coding account with explaining the impact of some social factors, Dolk et al. (2013a) suggested a more comprehensive referential coding account. In the following, we will introduce the basic assumptions of the referential coding account and illustrate how this account may be able to integrate the available evidence on the JSE.

Performing a (joint or solo) Simon task requires the preparation and selection of intentional actions. According to ideomotor theories of action control (Prinz, 1987; Hommel et al., 2001; Hommel, 2010), actions are represented by codes of their sensory consequences. In particular, TEC (Hommel et al., 2001) assumes that cognitive action representations consist of networks of codes representing the features of all perceivable effects, such as the seen, heard or felt location, direction and speed of an action, the effector it involves, the object it may relate to, and so forth (Hommel, 1997). Action control operates on these perceptual representations and action selection consists in activating the codes of the to-be-generated action effects (i.e., of the perceptual consequences of the action).

Importantly for our purposes, this rationale of representation implies that one's own actions and the actions of another person are basically represented in the same way (i.e., by means of the same kinds of codes; Hommel, 2009, 2011; see Figure 1). If we assume that response conflict reflects the concurrent activation of more than one action representation (e.g., because of endogenous preparation, stimulus-induced activation, and/or cross talk), this means that actively representing another person's action can create the same kind of response conflict than actively representing more than one of one's own possible actions. In other words, what matters for response conflict is the number of concurrently active action representations but not the source of the activation.

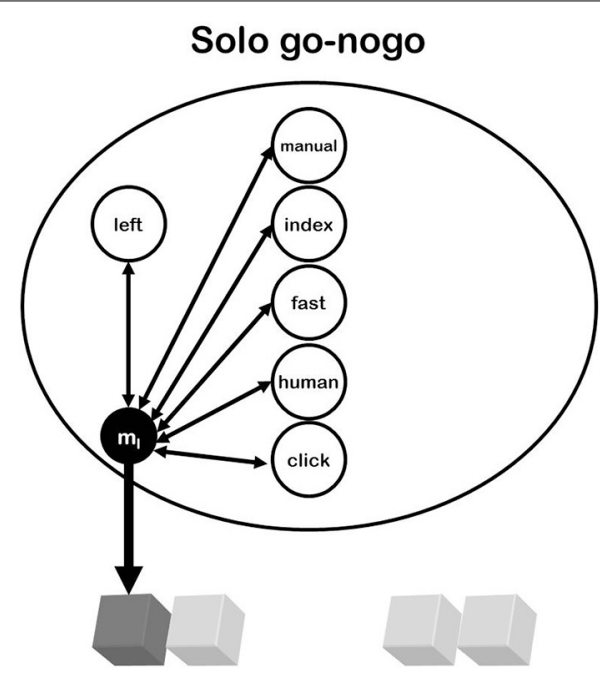

FIGURE 1 | Referential coding in the go-nogo versions of the Simon task. The figure shows tasks in which the agent operates the left response key. In the Solo version, a left keypress produces numerous action effects (i.e., something manual and fast, with an index finger moving, something human on the left that comes with a clicking sound, etc.) and can thus be coded in many ways; i.e., be represented by any of these and other action effects. In the Joint condition, the same action effects are produced and could be used

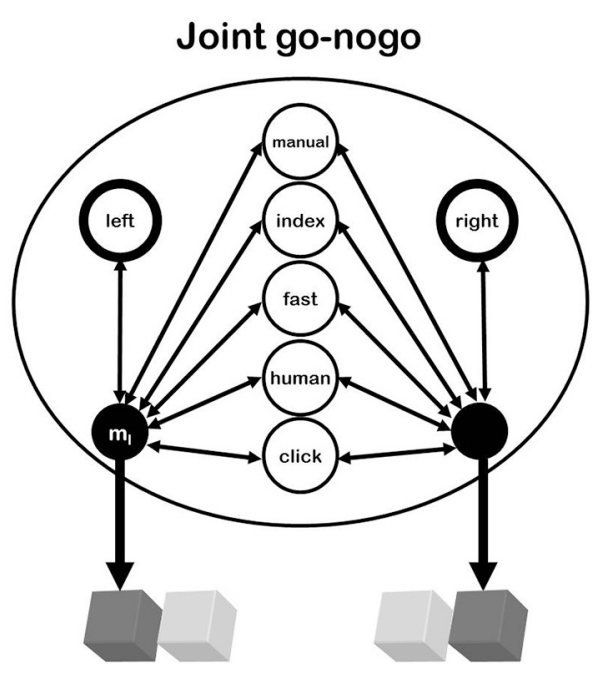

for referential coding, but most of them are shared by the other, alternative event. With one exception: the location. Discriminating between the two action events thus requires emphasizing (attending to, weighting more strongly) the corresponding (response) location. This makes the left keypress to be represented mainly as "left." Any event sharing that feature (such as a target stimulus on the left side) will thus activate the corresponding action more strongly in the Joint than in the Solo task-the Joint Simon effect. 
What the actor eventually needs to do is to select the taskrelevant action representation from all concurrently activated representations. Concurrent activation thus creates a discrimination problem, which requires a strong focus on those features that discriminate best between task-relevant and task-irrelevant representations (see Ansorge and Wühr, 2004 for a response discrimination account of the standard Simon effect). In the classical Simon task, the most obvious discriminating feature is horizontal location. As a consequence, people are likely to code their responses as "left" and "right," which equips the active action representations with spatial codes that can interact with equivalent spatial stimulus codes-which in turn creates a SE (Hommel et al., 2001). Rendering the task into a go-nogo task by having participants to respond to only one of the two stimuli by performing just one of the two responses eliminates the responsediscrimination problem, as now there is just one response being observed and to be executed. Accordingly, there is no need to code responses as "left" or "right" anymore, which explains why the SE typically disappears (Hommel, 1996).

However, as soon as an alternative action is made available, as in the social or non-social go-nogo-Simon task, the discrimination problem is back. Given the typically arranged (joint) workspace (i.e., horizontally or vertically; e.g., Dittrich et al., 2013), it appears reasonable that participants will again emphasize the discriminating features of their responses (i.e., through an increased "intentional weighting" of spatial features; Hommel et al., 2001; Yamaguchi and Proctor, 2012; Memelink and Hommel, 2013; see Figure 1) and thereby code their responses as "left" or "right." Thus, quite similar to the standard Simon task, an alternative response provides the most obvious reference frame, an assumption we share with the response coding account (e.g., Guagnano et al., 2010). As one would expect from this consideration, no JSE is obtained if participants always react together, so that the two responses need not be discriminated (Lam and Chua, 2009), or if the left-right arrangement of the responses does not match the (vertical) arrangement of the stimuli (Dittrich et al., 2012, 2013).

As TEC does not distinguish between merely perceived events and self-generated events (i.e., perceptions and actions), or between social and non-social events (i.e., living beings and objects), the referential coding account can easily accommodate the observation that non-social events can induce a JSE (Dolk et al., 2011, 2013a). In fact, any representation can create conflict with a representation of the currently (most) relevant response if it is sufficiently active. This implies that the represented event would need to be attended and/or sufficiently salient, which obviously applies to a Japanese waving cat and a ticking metronome, and thus accounts for the observation that nonsocial events can induce JSEs much like the presence of another human does (Dolk et al., 2013a), but less so to a distant co-actor (Guagnano et al., 2010). Since the referential coding account does not only account for the ability of these and other non-social events to elicit a JSE (see also Tsai et al., 2011; Dittrich et al., 2012), it also explains why the effect decreases with decreasing similarity between perceived and to-be-executed action events (Dolk et al., 2011, 2013a): the more similar two given (action) event representations (anticipated or perceived effects) are the stronger is the cross talk between them. In other words, representations of similar action events are more difficult to discriminate, which makes it more likely that the most obvious and parsimonious event-feature: spatial location is used to help with the discrimination. This rationale also accounts for the more pronounced JSEs in human-human interactions compared to interactions with a computer (Tsai et al., 2008), a machine-like robot (Stenzel et al., 2012), or a puppet (Tsai and Brass, 2007): action events produced by non-human, inanimate entities simply exhibit a lesser degree of (perceptual and/or conceptual) similarity with human actions (see Figure 1). It also explains why robot- or puppet-induced JSEs increase in size if these "co-actors" are made to behave intentionally (Stenzel et al., 2012) or otherwise more human-like (Müller et al., 2011a).

As we have discussed above, a number of social factors have been shown to affect the JSE. How does referential coding account for these observations? According to TEC's cognitive binding principle (Hommel, 2004), cognitive representations integrate concurrently active feature codes. It is this principle that accounts for the integration of motor patterns with codes of their perceptual consequences-the key assumption of ideomotor theory (Hommel, 2009). While codes related to immediate action consequences are likely to be activated by performance of the given action, these codes will not be the only ones being active at that time. People can clearly distinguish between their own actions and those carried out by others (even if not all representational systems reflect that difference), which means that codes representing themselves (their body, affective state, goals, etc.) are integrated to some degree with action representations, which provides additional means to discriminate between self-generated and other-generated actions. Again, the self-related codes can overlap with other-related codes to various degrees, depending on the perceived similarity between me and other (see Figure 1). According to the rationale explained above, more similarity would make the discrimination more difficult, which in turn would require more emphasis on the discriminating spatial features. As this emphasis should increase the JSE, this would imply that greater perceived similarity between actor and co-actor should increase the JSE. Note that while the application of this reasoning to the JSE refers to the coding of location (the only obvious candidate in the standard JSE task), any other feature can serve this function, too, as long as it enables sufficient discrimination between (stimulus- and/or action) event-alternatives, and thus provides a reference for coding one's own actions (see, Sellaro et al., under review, for a feature other than location, i.e., color).

As we have discussed already, various observations have confirmed this prediction. Given that interpersonal relationships (e.g., Mikulincer et al., 1998) and group membership (e.g., Aron et al., 1991; Avenanti et al., 2010) have been shown to increase perceived self-other overlap (Davis et al., 1996) and induce a more positive evaluation of the other (Brewer, 1979), it is reasonable to assume that a positive relationship between co-acting individuals or positive mood leads to greater perceived similarity (Heider, 1958). This explains the larger JSEs found under such conditions (Hommel et al., 2009; Kuhbandner et al., 2010), and it accounts for both the disappearance of the JSE when interacting with an 
out-group member (Müller et al., 2011b) and the reappearance of the effect after instructing participants to take the out-group member's perspective (Müller et al., 2011b).

Taken together, the principle of the referential coding account can be generalized to the following assumption: Self- and othergenerated events are cognitively represented by means of codes describing their perceptual features and the perceivable effects they create (e.g., attitude, color, direction, emotions, location, orientation, shape, speed and any other personal and nonpersonal characteristics; Dolk et al., 2011; Colzato et al., 2012a,b; Hommel, 2013). The degree of similarity would then not necessarily be a qualitative, but rather a gradual one (Hommel, 2013). Accordingly, increasing the degree of similarity increases the demand of discriminating alternative event-representations, leading to larger JSEs. This is an interesting methodological implication: The size of the JSE might be taken as an indicator of the similarity between (self- and other-generated) alternative events, and as a measure of the degree of self-other integration, particularly in social contexts-which in turn might make the go-nogo Simon paradigm a valuable educational or rehabilitative tool (Humphreys and Bedford, 2011; Liepelt et al., 2012).

\section{KEY CONCEPT 5 | Event-representations}

According to the Theory of Event Coding (TEC) events (self- and/or othergenerated) are cognitively represented by means of codes describing their perceptual features and the perceivable effects they create (e.g., attitude, belief, color, desire, emotion, orientation, shape, sound, speed, and any other characteristics).

\section{ACKNOWLEDGMENTS}

This work was supported by the German Research Foundation grants DFG LI 2115/1-1; 1-3 awarded to Roman Liepelt.

\section{REFERENCES}

Adolphs, R. (2003). Cognitive neuroscience of human social behaviour. Nat. Rev. Neurosci. 4, 165-178. doi: 10.1038/nrn1056

Amodio, D. M., and Frith, C. D. (2006). Meeting of minds: the medial frontal cortex and social cognition. Nat. Rev. Neurosci. 7, 268-277. doi: 10.1038/nrn1884

Ansorge, U., and Wühr, P. (2004). A response-discrimination account of the Simon effect. J. Exp. Psychol. Hum. Percep. Perform. 30, 365-377. doi: 10.1037/00961523.30.2.365

Aron, A., Aron, E. N., Tudor, M., and Nelson, G. (1991). Close relationships as including other in the self. J. Pers. Soc. Psychol. 60, 241-253. doi: 10.1037/00223514.60.2.241

Avenanti, A., Sirigu, A., and Aglioti, S. M. (2010). Racial bias reduces empathic sensorimotor resonance with other-race pain. Curr. Biol. 20, 1018-1022. doi: 10.1016/j.cub.2010.03.071

Bokura, H., Yamaguchi, S., and Kobayashi, S. (2001). Electrophysiological correlates for response inhibition in a Go/NoGo task. Clin. Neurophysiol. 112, 2224-2232. doi: 10.1016/S1388-2457(01)00691-5

Brass, M., and Heyes, C. M. (2005). Imitation: is cognitive neuroscience solving the correspondence problem? Trends Cogn. Sci. 9, 489-495. doi: 10.1016/j.tics.2005.08.007

Brewer, M. B. (1979). In-group bias in the minimal intergroup situation: a cognitive motivational analysis. Psychol. Bull. 86, 307-324. doi: 10.1037/00332909.86.2.307

Cavallo, A., Catmur, C., Sowden, S., Iani, F., and Becchio, C. (2014). Stopping movements: when others slow us down. Euro. J. Neurosci. 1-8, 2014 doi: 10.1111/ejn.12645

Coles, M. G. H. (1989). Modern mind-brain reading: psychophysiology, physiology, and cognition. Psychophysiology 26, 251-269. doi: 10.1111/j.14698986.1989.tb01916.x
Colzato, L. S., De Bruijn, E., and Hommel, B. (2012b). Up to "me" or to "us"? The impact of self-construal priming on cognitive self-other integration. Front. Psychol. 3:341. doi: 10.3758/s13423-012-0241-y

Colzato, L. S., van den Wildenberg, W. P. M., and Hommel, B. (2013). Increasing self-other integration through divergent thinking. Psychon. Bull. Rev. 20, 1011-1016. doi: 10.3758/s13423-013-0413-4

Colzato, L. S., Zech, H., Hommel, B., Verdonschot, R., van den Wildenberg, W. P. M., and Hsieh, S. (2012a). Loving-kindness brings loving-kindness: the impact of Buddhism on cognitive self-other integration. Psychon. Bull Rev. 19, 541-545. doi: 10.3758/s13423-012-0241-y

Davis, M. H., Conklin, L., Smith, A., and Luce, C. (1996). Effects of perspective taking on the cognitive representation of persons: a merging of self and other. J. Pers. Soc. Psychol. 70, 713-726. doi: 10.1037/0022-3514.70.4.713

De Jong, R., Liang, C. C., and Lauber, E. (1994). Conditional and unconditional automaticity: a dual-process model of effects of spatial stimulus-response correspondence. J. Exp. Psychol. Hum. Percep. Perform. 20, 731-750.

Dittrich, K., Dolk, T., Rothe-Wulf, A., Klauer, K. C., and Prinz, W. (2013). Keys and seats: spatial response coding underlying the joint spatial compatibility effect. Atten. Percept. Psychophys. 75, 1725-1736. doi: 10.3758/s13414-0130524-Z

Dittrich, K., Rothe, A., and Klauer, K. C. (2012). Increased spatial salience in the social Simon task: a response coding account of spatial compatibility effects. Atten. Percept. Psychophys.74, 911-929. doi: 10.3758/s13414-012-0304-1

Dolk, T., Hommel, B., Colzato, L. S., Schütz-Bosbach, S., Prinz, W., and Liepelt, R. (2011). How "social" is the social Simon effect? Front. Psychol. 2:84. doi: 10.3389/fpsyg.2011.00084

Dolk, T., Hommel, B., Prinz, W., and Liepelt, R. (2013a). The (not so) social Simon Effect: a referential coding account. J. Exp. Psychol. Hum. Percep. Perform. 39, 1248-1260. doi: 10.1037/a0031031

Dolk, T., Liepelt, R., Prinz, W., and Fiehler, K. (2013b). Visual experience determines the use of external reference frames in joint action control. PLoS ONE 8:e59008. doi: 10.1371/journal.pone.0059008

Dolk, T., Liepelt, R., Villringer, A., Prinz, W., and Ragert, P. (2012). Morphometric gray matter differences of the medial frontal cortex influence the social Simon effect. Neuroimage 61, 1249-1254. doi: 10.1016/j.neuroimage.2012. 03.061

Epley, N., Waytz, A., and Cacioppo, J. T. (2007). On seeing human: a three-factor theory of anthropomorphism. Psychol. Rev. 114, 864-886. doi: 10.1037/0033295X.114.4.864

Falkenstein, M., Koshlykova, N. A., Kiroj, V. N., Hoormann, J., and Hohnsbein, J. (1995). Late ERP components in visual and auditory Go/NoGo tasks. Electroencephalogr. Clin. Neurophysiol. 96, 36-43. doi: 10.1016/0013-4694(94)00182-K

Ferraro, L., Iani, C., Mariani, M., Milanese, N., and Rubichi, S. (2011). Facilitation and interference components in the joint Simon task. Exp. Brain Res. 211, 337-343. doi: 10.1007/s00221-011-2711-2

Ferraro, L., Iani, C., Mariani, M., Nicoletti, R., Gallese, V., and Rubichi, S. (2012) Look what I am doing: does observational learning take place in evocative tasksharing situations? PLoS ONE 7:e43311. doi: 10.1371/journal.pone.0043311

Frith, C. D., and Frith, U. (2007). Social cognition in humans. Curr. Biol. 17, 724-732. doi: 10.1016/j.cub.2007.05.068

Frith, C. D., and Wolpert, D. M. (2004). The Neuroscience of Social Interaction: Decoding, Imitating, and Influencing the Actions of Others. Oxford: Oxford University Press.

Frith, U. (2001). Mind blindness and the brain in autism. Neuron 32, 969-979. doi: 10.1016/S0896-6273(01)00552-9

Frith, U., and Frith, C. D. (2010). The social brain: allowing humans to boldly go where no other species has been. Philos. Trans. R. Soc. Lond. B Biol. Sci. 365 165-175. doi: 10.1098/rstb.2009.0160

Guagnano, D., Rusconi, E., and Umiltà, C. A. (2010). Sharing a task or sharing space? On the effect of the confeder-ate in action coding in a detection task. Cognition 114, 348-355. doi: 10.1016/j.cognition.2009.10.008

Hasson, U., Ghazanfar, A. A., Galantucci, B., Garrod, S., and Keysers, C. (2012). Brain-to-brain coupling: a mechanism for creating and sharing a social world. Trends Cogn. Sci. 16, 114-121. doi: 10.1016/j.tics.2011.12.007

Heider, F. (1958). The Psychology of Interpersonal Relations. New York, NY: Wiley. doi: 10.1037/10628-000

Hommel, B. (1993). The role of attention for the Simon effect. Psychol. Res. 55, 208-222. doi: 10.1007/BF00419608 
Hommel, B. (1996). S-R compatibility effects without response uncertainty. Q. J. Exp. Psychol. 49A, 546-571. doi: 10.1080/713755643

Hommel, B. (1997). "Toward an action-concept model of stimulus-response compatibility," in Theoretical Issues in Stimulus-Response Compatibility, eds B. Hommel and W. Prinz (Amsterdam: North-Holland), 281-320.

Hommel, B. (2004). Event files: feature binding in and across perception and action. Trends Cogn. Sci. 8, 494-500. doi: 10.1016/j.tics.2004.08.007

Hommel, B. (2009). Action control according to TEC (theory of event coding). Psychol. Res. 73, 512-526. doi: 10.1007/s00426-009-0234-2

Hommel, B. (2010). "Grounding attention in action control: the intentional control of selection," in Effortless Attention: a New Perspective in the Cognitive Science of Attention and Action, ed B. J. Bruya (Cambridge, MA: MIT Press), 121-140

Hommel, B. (2011). The Simon effect as tool and heuristic. Acta Psychol. 136, 189-202. doi: 10.1016/j.actpsy.2010.04.011

Hommel, B. (2013). "Ideomotor action control: on the perceptual grounding of voluntary actions and agents," in Action science: Foundations of an emerging discipline, eds W. Prinz, M. Beisert, and A. Herwig (Cambridge, MA: MIT Press), $113-136$

Hommel, B., Colzato, L. S., and van den Wildenberg, W. P. M. (2009). How social are task representations. Psychol. Sci. 20, 794-798. doi: 10.1111/j.14679280.2009.02367.x

Hommel, B., Müsseler, J., Aschersleben, G., and Prinz (2001). The theory of event coding (TEC): a framework for perception and action planning. Behav. Brain Sci. 24, 849-878. doi: 10.1017/S0140525X01000103

Humphreys, G. W., and Bedford, J. (2011). The relations between joint action and theory of mind: a neuropsychological analysis. Exp. Brain Res. 211, 357-369. doi: 10.1007/s00221-011-2643-x

Iani, C., Anelli, F., Nicoletti, R., Arcuri, L., and Rubichi, S. (2011). The role of group membership on the modulation of joint action. Exp. Brain Res. 211, 439-445. doi: 10.1007/s00221-011-2651-x

Knoblich, G., and Sebanz, N. (2006). The social nature of perception and action. Curr. Dir. Psychol. Sci. 15, 99-104. doi: 10.1111/j.0963-7214.2006.00415.x

Kornblum, S., Hasbroucq, T., and Osman, A. (1990). Dimensional overlap: cognitive basis for stimulus-response compatibility-A model and taxonomy. Psychol. Rev. 97, 253-270. doi: 10.1037/0033-295X.97.2.253

Kuhbandner, C., Pekrun, R., and Maier, M. A. (2010). The role of positive and negative affect in the "mirroring" of other persons' actions. Cogn. Emot. 24, 1182-1190. doi: 10.1080/02699930903119196

Lam, M. Y., and Chua, R. (2009). Influence of stimulus-response assignment on the joint-action correspondence effect. Psychol. Res. 74, 476-480. doi: 10.1007/ s00426-009-0269-4

Liepelt, R., Prinz, W., and Brass, M. (2010). When do we simulate nonhuman agents? Dissociating communicative and non-communicative actions. Cognition 115, 426-434. doi: 10.1016/j.cognition.2010.03.003

Liepelt, R., Schneider, J., Aichert, D. S., Wöstmann, N., Dehning, S., Möller, H.-J., et al. (2012). Action blind: disturbed self-other integration in schizophrenia. Neuropsychologia 50 3775-3780. doi: 10.1016/j.neuropsychologia.2012. 10.027

Liepelt, R., von Cramon, D. Y., and Brass, M. (2008a). What is matched in direct matching? Intention attribution modulates motor priming. J. Exp. Psychol. Hum. Percept. Perform. 34, 578-591. doi: 10.1037/0096-1523.34.3.578

Liepelt, R., von Cramon, D. Y., and Brass, M. (2008b). How do we infer others' goals from non-stereotypic actions? The outcome of context-sensitive inferential processing in right inferior parietal and posterior temporal cortex. Neuroimage 43, 784-792. doi: 10.1016/j.neuroimage.2008.08.007

Liepelt, R., Wenke, D., and Fischer, R. (2013). Effects of feature integration in a hands-crossed version of the social Simon paradigm. Psychol. Res. 77, 240-248. doi: 10.1007/s00426-012-0425-0

Liepelt, R., Wenke, D., Fischer, R., and Prinz, W. (2011). Trial-to- trial sequential dependencies in a social and non-social Simon task. Psychol. Res. 75, 366-375. doi: $10.1007 / \mathrm{s} 00426-010-0314-3$

Memelink, J., and Hommel, B. (2013). Intentional weighting: a basic principle in cognitive control. Psychol. Res. 77, 249-259. doi: 10.1007/s00426-012-0435-y

Mikulincer, M., Orbach, I., and Iavnieli, D. (1998). Adult attachment style and affect regulation: strategic variations in subjective self-other similarity. J. Pers. Soc. Psychol. 75, 436-448. doi: 10.1037/0022-3514.75.2.436

Milanese, N., Iani, C., and Rubichi, S. (2010). Shared learning shapes human performance: transfer effects in task sharing. Cognition 116, 15-22. doi: 10.1016/j.cognition.2010.03.010
Milanese, N., Iani, C., Sebanz, N., and Rubichi, S. (2011). Contextual determinants of the social transfer-of-learning effect. Exp. Brain Res. 211, 415-422. doi: 10.1007/s00221-011-2679-y

Müller, B. C. N., Brass, M., Kühn, S., Tsai, C. C., Nieuwboer, W., Dijksterhuis, A., et al. (2011a). When Pinocchio acts like a human, a wooden hand becomes embodied. action co-representation for non-biological agents. Neuropsychologia 49, 1373-1377. doi: 10.1016/j.neuropsychologia.2011.01.022

Müller, B. C. N., Kühn, S., van Baaren, R. B., Dotsch, R., Brass, M., and Dijksterhuis, A. (2011b). Perspective taking eliminates differences in corepresentation of out-group members' actions. Exp. Brain Res. 211, 423-428. doi: 10.1007/s00221-011-2654-7

Nicoletti, R., and Umiltà, C. (1989). Splitting visual space with attention. J. Exp. Psychol. Hum. Percep. Perform. 15, 164-169.

Nicoletti, R., and Umiltà, C. (1994). Attention shifts produce spatial stimulus codes. Psychol. Res. 56, 144-150.

Philipp, A. M., and Prinz, W. (2010). Evidence for a role of the responding agent in the joint compatibility effect. Q. J. Exp. Psychol. 63, 2159-2171. doi: 10.1080/ 17470211003802426

Poortvliet, P. M., and Darnon, C. (2010). Toward a more social understanding of achievement goals: the interpersonal effects of mastery and performance goals. Curr. Dir. Psychol. Sci. 19, 324-328. doi: 10.1177/0963721410383246

Premack, D., and Woodruff, G. (1978). Does the chimpanzee have a theory of mind? Behav. Brain Sci. 4, 515-526. doi: 10.1017/S0140525X00076512

Prinz, W. (1987). "Ideo-motor action," in Perspectives on Perception and Action, eds H. Heuer and A. F. Sanders (Hillsdale: Erlbaum), 47-76).

Prinz, W. (1990). "A common coding approach to perception and action," in Relationships between Perception and Action, eds O. Neumann and W. Prinz (Berlin: Springer), 167-201

Prinz, W. (1992). Why don't we perceive our brain states? Eur. J. Cogn. Psychol. $4,1-20$.

Prinz, W. (1997). Perception and action planning. Eur. J. Cogn. Psychol. 9, 129-154. doi: 10.1080/713752551

Proctor, R. W., and Vu, K.-P. L. (2006). Stimulus-Response Compatibility Principles: Data, Theory, and Applications. Boca Raton, FL: Taylor and Francis.

Radke, S., de Lange, F. P., Ullsperger, M., and De Bruijn, E. R. A. (2011). Mistakes that affect others: an fMRI study on processing of own errors in a social context. Exp. Brain Res. 211, 405-413. doi: 10.1007/s00221-011-2677-0

Ruys, K. I., and Aarts, H. (2010). When competition merges people's behavior: interdependency activates shared action representations. J. Exp. Soc. Psychol. 46, 1130-1133. doi: 10.1016/j.jesp.2010.05.016

Sebanz, N., Bekkering, H., and Knoblich, G. (2006a). Joint actions: bodies and minds moving together. Trends Cogn. Sci. 10, 70-76. doi: 10.1016/j.tics.2005. 12.009

Sebanz, N., and Knoblich, G. (2009). Prediction in joint action: what, when, and where. Topics Cogn. Sci. 1, 353-367. doi: 10.1111/j.1756-8765.2009.01024.x

Sebanz, N., Knoblich, G., and Prinz, W. (2003). Representing others'actions: just like one's own? Cognition 88, B11-B21. doi: 10.1016/S0010-0277(03) 00043-X

Sebanz, N., Knoblich, G., and Prinz, W. (2005a). How to share a task: corepresenting Stimulus-Response Mapping. J. Exp. Psychol Hum. Percep. Perform. 31, 1234-1246. doi: 10.1037/0096-1523.31.6.1234

Sebanz, N., Knoblich, G., Prinz, W., and Wascher, E. (2006b). Twin Peaks: an ERP study of action planning and control in coacting individuals. J. Cogn. Neurosci. 18, 859-870. doi: 10.1162/jocn.2006.18.5.859

Sebanz, N., Knoblich, G., Stumpf, L., and Prinz, W. (2005b). Far from action blind: representation of others' action in individuals with autism. Cogn. Neuropsychol. 22, 433-454. doi: 10.1080/02643290442000121

Sebanz, N., Rebbechi, D., Knoblich, G., Prinz, W., and Frith, C. D. (2007). It is really my turn? An event-related fMRI study of task sharing. Soc. Neurosci 2, 81-95. doi: 10.1080/17470910701237989

Sellaro, R., Treccani, B., Rubichi, S., and Cubelli, R. (2013). When co-action eliminates the Simon effect: disentangling the impact of co-actor's presence and task sharing on joint-task performance. Front. Psychol. 4:844. doi 10.3389/fpsyg.2013.00844

Shaw, E. (1978). Schooling fishes. Am. Sci. 66, 166-175.

Simon, J. R. (1969). Reactions toward the source of stimulation. J. Exp. Psychol. 81, 174-176. doi: 10.1037/h0027448

Simon, J. R. (1990). "The effects of an irrelevant directional cue on human information processing," in Stimulus- response Compatibility: An Integrated Perspective. 
Advances in Psychology, Vol. 65, eds R. W. Proctor and T. G. Reeve (Amsterdam: North-Holland), 31-86

Simon, J. R., and Craft, J. L. (1970). Effect of an irrelevant auditory stimulus in visual choice reaction time. J. Exp. Psychol. 86, 272-274. doi: 10.1037/ h0029961

Spengler, S., von Cramon, D. Y., and Brass, M. (2009). Control of shared representations relies on key processes involved in mental state attribution. Hum. Brain Mapp. 30, 3704-3718. doi: 10.1002/hbm.20800

Stenzel, A., Chinellato, E., Tirado Bou, M. A., del Pobil, Á. P., Lappe, M., and Liepelt, R. (2012). When humanoid robots become human-like interaction partners: co-representation of robotic actions. J. Exp. Psychol. Hum. Percep. Perform. 38, 1073-1077. doi: 10.1037/a0029493

Stenzel, A., Dolk, T., Colzato, L. S., Sellaro, R., Hommel, B., and Liepelt, R. (2014). The joint Simon effect depends on perceived agency, but not intentionality, of the alternative action. Front. Hum. Neurosci. 8:595. doi: 10.3389/fnhum.2014. 00595

Tomasello, M. (2009). Why We Cooperate. Cambridge. MA: MIT Press.

Tomasello, M., Carpenter, M., Call, J., Behne, T., and Moll, H. (2005). Understanding and sharing intentions: the origins of cultural cognition. Behav. Brain Sci. 28, 675-735. doi: 10.1017/S0140525X05000129

Tsai, C. C., and Brass, M. (2007). Does the human motor system simulate Pinocchio's actions? Psychol. Sci. 18, 1058-1061. doi: 10.1111/j.14679280.2007.02025.x

Tsai, C. C., Kuo, W. J., Hung, D. L., and Tzeng, O. J. (2008). Action corepresentation is tuned to other humans. J. Cogn. Neurosci. 20, 2015-2024. doi: 10.1162/jocn.2008.20144

Tsai, C. C., Kuo, W. J., Jing, J. T., Hung, D. L., and Tzeng, O. J. (2006). A common coding framework in self-other interaction: evidence from joint action task. Exp. Brain Res. 175, 353-362. doi: 10.1007/s00221-0060557-9

Tsai, J. C.-C., Knoblich, G., and Sebanz, N. (2011). On the inclusion of externally controlled actions in action planning. J. Exp. Psychol. Hum. Percep. Perform. 37, 1407-1419. doi: 10.1037/a0024672

Van Overwalle, F. (2009). Social cognition and the brain: a meta-analysis. Hum. Brain Mapp. 30, 829-858. doi: 10.1002/hbm.20547

Vesper, C., Butterfill, S., Knoblich, G., and Sebanz, N. (2010). A minimal architecture for joint action. Neural Netw. 23, 998-1003. doi: 10.1016/cj.neunet.2010. 06.002
Vlainic, E., Liepelt, R., Colzato, L. S., Prinz, W., and Hommel, B. (2010). The virtual co-actor: the social Simon effect does not rely on online feedback from the other. Front. Psychol. 1:208. doi: 10.3389/fpsyg.2010.00208

Welsh, T. N. (2009). When $1+1=1$ : the unification of independent actors revealed through joint Simon effects in crossed and uncrossed effector conditions. Hum. Mov. Sci. 28, 726-737. doi: 10.1016/j.humov.2009.07.006

Welsh, T. N., Higgins, L., Ray, M., and Weeks, D. J. (2007). Seeing vs. believing: is believing sufficient to activate the processes of response co-representation? Hum. Mov. Sci. 26, 853-866. doi: 10.1016/j.humov.2007.06.003

Welsh, T. N., Kiernan, D., Neyedli, H. F., Ray, M., Potruff, A., Pratt, J., et al. (2013) Joint Simon effects in extrapersonal space. J. Mot. Behav. 45, 1-5. doi: 10.1080/ 00222895.2012.746635

Wenke, D., Atmaca, S., Holländer, A., Liepelt, R., Baess, P., and Prinz, W. (2011). What is shared in joint action? The contents of co-representation. Rev. Philos. Psychol. 2, 147-172. doi: 10.1007/s13164-011-0057-0

Wilson, M., and Knoblich, G. (2005). The case of motor involvement in perceiving conspecifics. Psychol. Bull. 131, 460-473. doi: 10.1037/0033-2909.131.3.460

Yamaguchi, M., and Proctor, R. W. (2012). Multidimensional vector models of stimulus-response compatibility. Psychol. Rev. 119, 272-303. doi: 10.1037/ a0026620

Conflict of Interest Statement: The authors declare that the research was conducted in the absence of any commercial or financial relationships that could be construed as a potential conflict of interest.

Received: 21 March 2014; accepted: 17 August 2014; published online: 05 September 2014

Citation: Dolk T, Hommel B, Colzato LS, Schütz-Bosbach S, Prinz W and Liepelt R (2014) The joint Simon effect: a review and theoretical integration. Front. Psychol. 5:974. doi: 10.3389/fpsyg.2014.00974

This article was submitted to the journal Frontiers in Psychology.

Copyright (C) 2014 Dolk, Hommel, Colzato, Schütz-Bosbach, Prinz and Liepelt. This is an open-access article distributed under the terms of the Creative Commons Attribution License (CC BY). The use, distribution or reproduction in other forums is permitted, provided the original author(s) or licensor are credited and that the original publication in this journal is cited, in accordance with accepted academic practice. No use, distribution or reproduction is permitted which does not comply with these terms. 